\title{
Iniciativas de Turismo Étnico Comunitario en pueblos inmigrantes de origen Alemán del Volga y Japonés
}

\author{
M. I. Varela \\ INDICAT Instituto de Investigaciones Científicas Aplicadas al Turismo. Universidad de Morón. \\ E-mail:varela4047@yahoo.com.ar
}

En línea con la investigación de Turismo Comunitario (TC) del INDICAT desde el año 2010, se han abordado el estudio de iniciativas de inmigrantes de origen alemán del Volga y japonés sobre la base de la categoría de Turismo Étnico e Indígena Comunitario (TEC) de Michel y Muckosy (2008).

En la investigación se plantearon dos objetivos; la detección y sistematización de la producción teórica; el relevamiento de los actores sociales; la configuración de un mapeo diagnóstico y el análisis de la potencialidad de desarrollo de experiencias TEC en el marco del INDICAT.

La hipótesis propuso que en la gestión sostenible de los proyectos de turismo étnico comunitario de inmigrantes de origen alemán del Volga y japonés prevalecen, por sobre otras motivaciones, el arraigo de los jóvenes en las zonas rurales, y la puesta en valor de la cultura de origen en la comunidad de acogida.

El marco teórico se analizó sobre la base de la teoría del Desarrollo Humano desarrollada por Amaryta Sen (1999) el marco de los Objetivos de Desarrollo Sustentable, Agenda 2030. Por otro, para los temas específicos se trabajaron los textos de Gómez García (1998), Giménez (2005), Melucci (2001), Flores (2003); Onaha (2007); Gómez et al. (2007); Irene Cafiero (2003); Stolen y Archetti (1975) y Minetti (2008).

El inventario del Patrimonio Cultural Material e Inmaterial se realizó en base a la metodología de la Organización para la Educación, la Ciencia y la Cultura (UNESCO; 2008) y la Organización de Estados Americanos (OEA) del Centro Interamericano de Capacitación Turística (CICATUR; 1979). Entre los resultados, se identificaron y mapearon las colonias en Argentina de origen alemán del Volga y japonés; se analizaron datos cuantitativos del Censo Nacional de la Población 2010 y se relevaron in situ, tres colonias de origen alemán del Volga en Coronel Suárez. Además, se generaron dos inventarios de Patrimonio Material e Inmaterial de las colonias estudiadas.

A modo de conclusión, las comunidades se exiliaron por la guerra 0 por motivos persecutorios ideológicos y políticos. Los recursos culturales y la afirmación de su identidad han sido valorados por estas comunidades desde hace siglos; por lo tanto, preceden al fenómeno turístico y no requieren ser promovidos de manera exógena. Esto aporta un componente de autenticidad único y les otorga gran potencial en términos de sustentabilidad.

Palabras Claves: desarrollo sustentable; turismo étnico comunitario; comunidad; etnia; identidad individual y colectiva; patrimonio cultural material e inmaterial. 